\title{
A Comparison of Statin Therapies in Hypercholesterolemia in Women: A Subgroup Analysis of the STELLAR Study
}

\author{
Francine K. Welty, MD, Sandra J. Lewis, MD, ${ }^{1}$ Karen E. Friday, MD, ${ }^{3}$ \\ Valerie A. Cain, MS, ${ }^{4}$ and Deborah A. Anzalone, MD ${ }^{4}$
}

\begin{abstract}
Objective: Cardiovascular disease is the leading cause of mortality in women in the United States. Aggressive treatment of modifiable risk factors (e.g., hypercholesterolemia) is essential in reducing disease burden. Despite guidelines recommending the use of statin treatment in hypercholesterolemic women, this patient group is often undertreated. This subgroup analysis of the Statin Therapies for Elevated Lipid Levels compared Across doses to Rosuvastatin (STELLAR) trial examines the effects of statin therapy in hypercholesterolemic women.

Methods: As part of the STELLAR trial, 1,146 women with elevated low-density lipoprotein cholesterol (LDL-C $\geq 160$ and $<250 \mathrm{mg} / \mathrm{dL}$ ) and triglycerides $<400 \mathrm{mg} / \mathrm{dL}$ were randomized to rosuvastatin $10-40 \mathrm{mg}$, atorvastatin $10-80 \mathrm{mg}$, simvastatin $10-80 \mathrm{mg}$, or pravastatin $10-40 \mathrm{mg}$ for 6 weeks.

Results: LDL-C reduction with rosuvastatin $10 \mathrm{mg}$, atorvastatin $10 \mathrm{mg}$, simvastatin $20 \mathrm{mg}$, and pravastatin $40 \mathrm{mg}$ was $49 \%, 39 \%, 37 \%$, and 30\%, respectively, after 6 weeks. High-intensity statins (rosuvastatin 20-40 mg and atorvastatin $40-80 \mathrm{mg}$ ) reduced LDL-C to the greatest extent: $53 \%$ with rosuvastatin $20 \mathrm{mg}$, $57 \%$ with rosuvastatin $40 \mathrm{mg}$, $47 \%$ with atorvastatin $40 \mathrm{mg}$, and $51 \%$ with atorvastatin $80 \mathrm{mg}$. Similar results were observed for non-high-density lipoprotein cholesterol (non-HDL-C). Increases in HDL-C were greater with rosuvastatin across doses than with other statins. All treatments were well tolerated, with similar safety profiles across dose ranges. Conclusions: Statin therapies in the STELLAR trial led to reductions in LDL-C, non-HDL-C, and triglycerides and increases in HDL-C among hypercholesterolemic women, with rosuvastatin providing the greatest reductions in LDL-C and non-HDL-C.
\end{abstract}

\section{Introduction}

C ARDIOVASCULAR DISEASE (CVD) is the leading cause of mortality among women in the United States. ${ }^{1}$ While coronary heart disease (CHD) rates in women increase markedly with age, ${ }^{2,3}$ of particular concern is the increasing number of CHD deaths among US women aged 35-54 years, believed to be due to the increasing prevalence of obesity. ${ }^{4}$ Therefore, early identification and aggressive management of modifiable risk factors are essential to reduce the overall burden of CHD in women. ${ }^{5}$

Hypercholesterolemia is a major modifiable risk factor for CVD for both men and women. ${ }^{3}$ Low-density lipoprotein cholesterol (LDL-C) levels are typically lower in women than in men until menopause, when levels increase (from a mean of $117 \mathrm{mg} / \mathrm{dL}$ [ $3 \mathrm{mmol} / \mathrm{L}$ ] to $145 \mathrm{mg} / \mathrm{dL}[3.7 \mathrm{mmol} / \mathrm{L}])^{6}$ and LDL particles tend to become more atherogenic. ${ }^{7}$ High-density lipoprotein cholesterol (HDL-C) levels are approximately $10 \mathrm{mg} / \mathrm{dL}(0.3 \mathrm{mmol} / \mathrm{L})$ higher in women than in men, ${ }^{8}$ and low levels are more predictive of CHD in women compared with men, especially in women aged 65 years or older. ${ }^{3}$ Moreover, elevated triglycerides may be a more significant risk factor in women (especially older women) compared with men, ${ }^{4,9,10}$ and, for both sexes, elevated non-HDL-C is recognized as a risk marker for CHD, ${ }^{11}$ particularly in patients with hypertriglyceridemia, reflecting increased levels of atherogenic remnant very low-density lipoprotein (VLDL).

\footnotetext{
${ }^{1}$ Beth Israel Deaconess Medical Center, Harvard Medical School, Boston, Massachusetts.

${ }^{2}$ Northwest Cardiovascular Institute, Portland, Oregon.

${ }^{3}$ Louisiana State University School of Medicine, New Orleans, Louisiana.

${ }^{4}$ AstraZeneca, Wilmington, Delaware.
}

(c) Francine K. Welty, et al. 2016; Published by Mary Ann Liebert, Inc. This Open Access article is distributed under the terms of the Creative Commons Attribution Noncommercial License (http://creativecommons.org/licenses/by-nc/4.0/) which permits any noncommercial use, distribution, and reproduction in any medium, provided the original author(s) and the source are credited. 
Table 1. American Heart Association's RECOMMENDED LiPID PARAMETERS FOR WOMEN

\begin{tabular}{lc}
\hline Lipid & \multicolumn{1}{c}{ Recommended level } \\
\hline LDL-C & $<100 \mathrm{mg} / \mathrm{dL}(<2.6 \mathrm{mmol} / \mathrm{L})$ \\
HDL-C & $>50 \mathrm{mg} / \mathrm{dL}(>1.3 \mathrm{mmol} / \mathrm{L})$ \\
Triglycerides & $<150 \mathrm{mg} / \mathrm{dL}(<1.7 \mathrm{mmol} / \mathrm{L})$ \\
Non-HDL-C & $<130 \mathrm{mg} / \mathrm{dL}(<3.4 \mathrm{mmol} / \mathrm{L})$ \\
\hline
\end{tabular}

Source: Mosca et al., 2011. ${ }^{4}$

HDL-C, high-density lipoprotein cholesterol; LDL-C, lowdensity lipoprotein cholesterol.

Several guidelines recommend statins as first-line treatment for cholesterol reduction when diet and exercise are inadequate. ${ }^{4,12} \mathrm{~A}$ meta-analysis of 27 statin trials showed that a $39 \mathrm{mg} / \mathrm{dL}(1 \mathrm{mmol} / \mathrm{L})$ reduction in LDL-C was associated with a $16 \%$ (rate ratio $0.84,99 \%$ confidence interval [CI] $0.78-0.91$ ) reduction in major vascular events in women, similar to the $22 \%$ (rate ratio $0.78,99 \%$ CI $0.75-0.81$ ) reduction observed in men. ${ }^{13}$ Further analysis of 5 studies comparing more versus less intensive statin therapy revealed that major vascular events were reduced by $25 \%$ (rate ratio $0.75,99 \%$ CI $0.58-0.97)$ per $39 \mathrm{mg} / \mathrm{dL}(1 \mathrm{mmol} / \mathrm{L})$ reduction in LDL-C in women receiving more versus less intensive statin therapy, compared with $29 \%$ (rate ratio $0.71,99 \% \mathrm{CI}$ $0.63-0.80$ ) in men. ${ }^{13}$ Thus, although women derive a clear benefit from LDL-C reduction, ${ }^{14-16}$ available data indicate that women are undertreated for hypercholesterolemia. ${ }^{17,18}$

One reason for undertreatment may be underestimation of CVD risk in women. Standard risk stratification tools, such as

Table 2. American College of Cardiology/ American Heart Association StATIN-BENEFIT Groups

Statin-benefit group

Clinical ASCVD

Primary elevations of LDL-C $\geq 190 \mathrm{mg} / \mathrm{dL}$ $(4.9 \mathrm{mmol} / \mathrm{L})$

Diabetes aged 40-75 years and LDL-C $70-189 \mathrm{mg} / \mathrm{dL}$ $(1.8-4.1 \mathrm{mmol} / \mathrm{L})$, but without clinical ASCVD

Without clinical ASCVD or diabetes with LDL-C $70-189 \mathrm{mg} / \mathrm{dL}$ $(1.8-4.1 \mathrm{mmol} / \mathrm{L})$ and estimated 10-year ASCVD risk $\geq 7.5 \%$

Source: Stone et al., 2014. ${ }^{12}$

ASCVD, atherosclerotic cardiovascular disease; LDL-C, lowdensity lipoprotein cholesterol.
Table 3. American College of Cardiology/ American Heart Association Statin INTENSITY GUIDELINES

\begin{tabular}{llc}
\hline Intensity & \multicolumn{1}{c}{ Statin dose } & $\begin{array}{c}\text { Anticipated LDL-C } \\
\text { reduction }\end{array}$ \\
\hline High & $\begin{array}{l}\text { Rosuvastatin } 20-40 \mathrm{mg} \\
\text { Atorvastatin } 40-80 \mathrm{mg}\end{array}$ & $\geq 50 \%$ \\
Moderate & $\begin{array}{l}\text { Rosuvastatin 5-10 mg } \\
\text { Atorvastatin 10-20 mg }\end{array}$ & $30 \%-50 \%$ \\
\hline
\end{tabular}

Source: Stone et al., 2014. ${ }^{12}$

LDL-C, low-density lipoprotein cholesterol.

the Framingham risk score, are limited in that they focus on short-term (i.e., 10-year) risk of myocardial infarction and CHD death only, exclude family history, and overestimate or underestimate risk in non-white populations. This, together with the fact that subclinical CVD can have relatively high prevalence among women, means that many women under the age of 75 years may never exceed a predicted 10 -year risk for CHD of $\geq 10 \%$ and subsequently may not be considered for dyslipidemia treatment. ${ }^{4}$

Mindful of these limitations, the 2011 American Heart Association (AHA) evidence-based guidelines for CVD prevention in women recommend defining high risk in women as a 10 -year risk of $\geq 10 \%$ for all CVD, not just CHD alone. ${ }^{4}$ The guidelines also recommend that all women should be encouraged to reach ideal levels of four critical lipid parameters (Table 1) through lifestyle approaches. ${ }^{4}$ For high-risk women (i.e., those with CHD, cerebrovascular disease, peripheral arterial disease, abdominal aortic aneurysm, end-stage or chronic kidney disease, diabetes mellitus, or a predicted 10-year CVD risk $\geq 10 \%$ ), the addition of lipid-lowering pharmacotherapy is recommended if lifestyle changes alone are insufficient at reducing lipids to the ideal levels. ${ }^{4}$

More recently the AHA, in collaboration with the American College of Cardiology (ACC), published guidelines on the treatment of cholesterol to reduce atherosclerotic cardiovascular risk in adults (men and women). ${ }^{12}$ These guidelines identify patients and provide treatment recommendations according to four statin-benefit groups (Tables 2, 3).

The Statin Therapies for Elevated Lipid Levels compared Across doses to Rosuvastatin (STELLAR) trial (clinicaltrials.gov identifier: NCT00654537) compared rosuvastatin treatment with three other widely used statins (atorvastatin, simvastatin, and pravastatin) in a hypercholesterolemic patient population. ${ }^{19}$ This subgroup analysis examines the effects of statin therapy in improving lipid profiles in the hypercholesterolemic women who participated in the STELLAR trial. Because of its large number of female participants (51\%, $n=1,146)$, the STELLAR trial is particularly appropriate for this analysis.

\section{Materials and Methods}

The STELLAR trial was a randomized, parallel-group, open-label, comparator-controlled multicenter trial in 2,431 hypercholesterolemic patients. A detailed description of the methods of the trial is provided elsewhere. ${ }^{19}$ Briefly, after a 6-week dietary lead-in period, men and women aged 18 years 


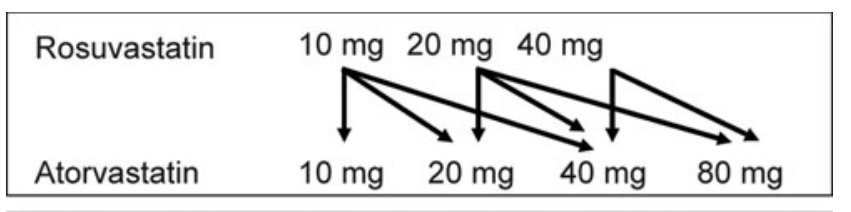

Rosuvastatin

Rosuvastatin $10 \mathrm{mg} 20 \mathrm{mg} 40 \mathrm{mg}$

FIG. 1. Pairwise comparisons for changes in lipids and achievement of lipid levels for rosuvastatin versus atorvastatin, simvastatin, and pravastatin.

or older with fasting LDL-C $\geq 160 \mathrm{mg} / \mathrm{dL}$ and $<250 \mathrm{mg} / \mathrm{dL}$ $(\geq 4.1 \mathrm{mmol} / \mathrm{L}$ and $<6.5 \mathrm{mmol} / \mathrm{L})$ and triglycerides $<400 \mathrm{mg} / \mathrm{dL}$ $(<4.5 \mathrm{mmol} / \mathrm{L})$, discontinued from all cholesterol-lowering drugs and dietary supplements, were randomized to 6 weeks of treatment with one of four statins.

The current subgroup analysis involves 1,146 women who began study treatment with rosuvastatin 10,20 , or $40 \mathrm{mg}$; atorvastatin $10,20,40$, or $80 \mathrm{mg}$; simvastatin $10,20,40$, or $80 \mathrm{mg}$; or pravastatin 10,20 , or $40 \mathrm{mg}$. To be included, all women had to have a baseline and at least one post-baseline lipid measurement. Changes in LDL-C, non-HDL-C, triglycerides, and HDL-C from baseline to 6 weeks were assessed by statin dose group. To compare changes in lipid levels among treatments, least-squares mean changes from baseline to 6 weeks for 22 pairwise comparisons of rosuvastatin 10,20 , or $40 \mathrm{mg}$ with milligram-equivalent or higher doses of comparator statins (Fig. 1) were obtained using a Bonferroni adjustment with a significance level of 0.002 to obtain an experiment-wise error rate of 0.05 . This is an adjustment for the 22 multiple comparisons $(0.05 / 22=0.002)$. For efficacy variables, the last observation was carried forward for those women not completing 6 weeks of treatment.

Safety evaluations are described in Jones et al. ${ }^{19}$ and involved assessment of clinical adverse events and laboratory values.

\section{Results}

\section{Patients}

Of the 1,146 women in this subgroup analysis from the STELLAR trial, 249 received rosuvastatin $10-40 \mathrm{mg}, 320$ received atorvastatin $10-80 \mathrm{mg}, 333$ received simvastatin $10-80 \mathrm{mg}$, and 244 received pravastatin $10-40 \mathrm{mg}$. Baseline characteristics are shown in Table 4 . Mean ages, 58-60 years, were similar across the statin groups. Most of these women were taking at least one concomitant medication. At baseline, mean LDL-C was $190 \mathrm{mg} / \mathrm{dL}(4.9 \mathrm{mmol} / \mathrm{L})$, indicating that the women had substantial hypercholesterolemia.

\section{Efficacy}

Statin treatment produced dose-related decreases in LDL$\mathrm{C}$ levels ranging from $21 \%$ to $57 \%$ at 6 weeks, depending on the statin and dose used (Fig. 2A). At the lowest statin dose, $10 \mathrm{mg}$, LDL-C was reduced by $49 \%$ with rosuvastatin, $39 \%$ with atorvastatin, $30 \%$ with simvastatin, and $21 \%$ with pravastatin ( $p<0.002$ rosuvastatin vs. all comparators). A similar pattern was observed for the high-intensity doses of statins defined by the ACC/AHA guideline and recommended for those at risk of atherosclerotic cardiovascular disease: ${ }^{12}$ LDL-C reductions were $53 \%$ with rosuvastatin $20 \mathrm{mg}, 57 \%$ with rosuvastatin $40 \mathrm{mg}$, $47 \%$ with atorvastatin $40 \mathrm{mg}$, and $51 \%$ with atorvastatin $80 \mathrm{mg}$. Rosuvastatin $20 \mathrm{mg}$ produced statistically greater reductions in LDL-C compared with atorvastatin $20 \mathrm{mg}$ and $40 \mathrm{mg}(p<0.002$ for both comparisons). In addition, rosuvastatin $40 \mathrm{mg}$ produced statistically greater reductions in LDL-C compared with atorvastatin $40 \mathrm{mg}(p<0.002)$.

Reductions in non-HDL-C levels ranged from $45 \%$ to $53 \%$ with rosuvastatin, $37 \%$ to $48 \%$ with atorvastatin, $27 \%$ to $44 \%$ with simvastatin, and $19 \%$ to $28 \%$ with pravastatin (Fig. 2B). Reductions in non-HDL-C with rosuvastatin $10 \mathrm{mg}$ were significantly greater when compared with atorvastatin $10 \mathrm{mg}$; simvastatin 10,20 , or $40 \mathrm{mg}$; and pravastatin 10,20 , or $40 \mathrm{mg}$ ( $p<0.002$ for all comparisons). Rosuvastatin $20 \mathrm{mg}$ reduced non-HDL-C significantly more than milligram-equivalent doses of atorvastatin, simvastatin, and pravastatin $(p<0.002$ for all comparisons).

The increases in HDL-C were numerically greater with rosuvastatin than with the other statins, but the differences were not statistically significant, except that rosuvastatin 20 and $40 \mathrm{mg}$ increased HDL-C significantly more than milligramequivalent or higher doses of atorvastatin (Fig. 2C).

All statins reduced triglyceride levels, with similar effects across the dose range for rosuvastatin and atorvastatin, and a trend for dose-related reductions for simvastatin and pravastatin. No significant differences in effect on triglycerides were observed between rosuvastatin and atorvastatin. However, rosuvastatin $10 \mathrm{mg}$ decreased triglycerides significantly more than simvastatin $10 \mathrm{mg}$, and pravastatin $10 \mathrm{mg}$ and $20 \mathrm{mg}$; rosuvastatin $20 \mathrm{mg}$ decreased triglycerides significantly more than $20 \mathrm{mg}$ of simvastatin and pravastatin (Fig. 2D) $(p<0.002$ for all comparisons).

\section{Safety}

All treatments were generally well tolerated, with similar safety profiles across treatments and dose ranges (Table 5). Study withdrawal due to drug-related treatment-emergent adverse events occurred in 5 rosuvastatin-treated women (2.0\%), 13 atorvastatin-treated women $(4.1 \%), 7$ simvastatintreated women $(2.1 \%)$, and 7 pravastatin-treated women (2.9\%). The most common adverse events were pain $(6.4 \%)$, pharyngitis $(5.4 \%)$, headache $(4.4 \%)$, and myalgia $(4.0 \%)$. There were no cases of rhabdomyolysis, myopathy, or clinically significant elevations ( $>10$ times the upper limit of normal) in serum creatine kinase in these women. Clinically significant elevations ( $>3$ times the upper limit of normal on two consecutive occasions) in alanine aminotransferase were infrequent, occurring in 1 patient receiving atorvastatin $20 \mathrm{mg}(1.3 \%), 2$ patients receiving atorvastatin $80 \mathrm{mg}(2.4 \%)$, and 1 patient receiving simvastatin $80 \mathrm{mg}(1.2 \%)$. No patients in this analysis had creatinine levels that increased $>100 \%$ from baseline, and no women had creatinine levels that were above the upper limit of normal. 
Table 4. Baseline Characteristics of 1,146 Women in the STELLAR Trial (Randomized Population)

\begin{tabular}{|c|c|c|c|c|}
\hline & $\begin{array}{c}\text { Rosuvastatin } \\
\text { 10-40 mg } \\
(\mathrm{n}=249)\end{array}$ & $\begin{array}{l}\text { Atorvastatin } \\
10-80 \mathrm{mg} \\
(\mathrm{n}=320)\end{array}$ & $\begin{array}{l}\text { Simvastatin } \\
10-80 \mathrm{mg} \\
(\mathrm{n}=333)\end{array}$ & $\begin{array}{c}\text { Pravastatin } \\
10-40 \mathrm{mg} \\
(\mathrm{n}=244)\end{array}$ \\
\hline \multicolumn{5}{|l|}{ Age (years) } \\
\hline Mean (SD) & $60(12)$ & $60(11)$ & $59(12)$ & $58(12)$ \\
\hline$>65$ years, $n(\%)$ & $87(35)$ & $131(41)$ & $111(33)$ & $80(33)$ \\
\hline \multicolumn{5}{|l|}{ Race, $\%$} \\
\hline White & 85 & 82 & 84 & 85 \\
\hline Black & 8 & 12 & 10 & 12 \\
\hline Hispanic & 5 & 3 & 4 & 2 \\
\hline Other & 1 & 3 & 2 & 2 \\
\hline Atherosclerosis, $n(\%)^{\mathrm{a}}$ & $35(14)$ & $46(14)$ & $50(15)$ & $27(11)$ \\
\hline Diabetes, $n(\%)$ & $15(6)$ & $27(8)$ & $26(8)$ & $22(9)$ \\
\hline Hypertension, $n(\%)$ & $111(45)$ & $165(52)$ & $166(50)$ & $113(46)$ \\
\hline \multicolumn{5}{|l|}{ Smoking history, $n(\%)$} \\
\hline Current smoker & $38(15)$ & $52(16)$ & $43(13)$ & $33(14)$ \\
\hline Former smoker & $63(25)$ & $95(30)$ & $108(32)$ & $80(33)$ \\
\hline $\begin{array}{l}\text { Family history of premature } \\
\text { CHD/PVD, } n(\%)\end{array}$ & $56(23)$ & $68(21)$ & $72(22)$ & $59(24)$ \\
\hline $\begin{array}{l}\text { Concomitant medications } \\
\quad(\text { pre-enrollment }), n(\%)^{\mathrm{b}}\end{array}$ & $247(99)$ & $308(96)$ & $323(97)$ & $238(98)$ \\
\hline \multicolumn{5}{|c|}{$\begin{array}{l}\text { Lipid and Apo values at baseline, } \\
\text { mg/dL; mean }(S D)^{c}\end{array}$} \\
\hline LDL-C & $192(19)$ & $190(20)$ & $191(19)$ & 189 (17) \\
\hline Non-HDL-C & $229(22)$ & $226(24)$ & $225(23)$ & $226(23)$ \\
\hline HDL-C & $55(11)$ & $55(12)$ & $55(12)$ & $53(12)$ \\
\hline Triglycerides & $184(69)$ & $179(66)$ & $171(60)$ & 189 (69) \\
\hline Apo B & $174(23)$ & $171(24)$ & $168(23)$ & $171(24)$ \\
\hline Apo A-I & $160(27)$ & $163(27)$ & $161(28)$ & $158(27)$ \\
\hline Apo B/Apo A-I & $1.1(0.2)$ & $1.1(0.2)$ & $1.1(0.2)$ & $1.1(0.2)$ \\
\hline
\end{tabular}

${ }^{a}$ History of angina, myocardial infarction, cerebrovascular accident, transient ischemic attack, or intermittent claudication, or any documented carotid artery, peripheral vascular, or coronary artery disease.

${ }^{\mathrm{b}}$ The most common concomitant medications were 3-hydroxy-3-methylglutaryl-coenzyme A (HMG CoA) reductase inhibitors (39.9\%); analgesics and antipyretics, salicylic acid and derivatives (29.7\%); multivitamins, other combinations (25.3\%); other plain vitamin preparations (22.8\%); calcium supplement (21.3\%); analgesics, antipyretics, anilides (20.2\%); propionic acid derivatives (20.2\%); natural and semisynthetic estrogens (16.5\%); thyroid hormones (13.4\%); selective serotonin reuptake inhibitors (13.3\%); COX-2 inhibitors (12.8\%); proton pump inhibitors (12.7\%); ACE inhibitors (11.4\%); ascorbic acid (vitamin C) (11.4\%).

${ }^{\mathrm{c}}$ Numbers of patients for whom lipid data are available are 247, 317, 330, and 239 for rosuvastatin, atorvastatin, simvastatin, and pravastatin, respectively; number available for apolipoproteins are 241, 309, 326, and 235, respectively.

Apo, apolipoprotein; PVD, peripheral vascular disease; SD, standard deviation; STELLAR, Statin Therapies for Elevated Lipid Levels compared Across doses to Rosuvastatin.

\section{Discussion}

To our knowledge, this is the first large-scale comparative subgroup analysis of the lipid-lowering effects of statins across their dose ranges in hypercholesterolemic women in a clinical trial population. As in the total STELLAR population, ${ }^{19,20}$ rosuvastatin $10-40 \mathrm{mg}$ reduced LDL-C and non-HDL-C more than milligram-equivalent doses of atorvastatin, and milligram-equivalent and higher doses of simvastatin and pravastatin. In our analysis, mean baseline LDL-C was $190 \mathrm{mg} / \mathrm{dL}(4.9 \mathrm{mmol} / \mathrm{L})$, indicating that the women had substantial hypercholesterolemia, with many of them fulfilling the ACC/AHA 2013 guideline criteria for high-intensity statin therapy according to their baseline LDL-C levels alone, irrespective of other risk factors.

Although the 2011 AHA and 2013 ACC/AHA lipid guidelines represent important directives in preventive cardiovascular care for women ${ }^{4,12}$ and awareness of CVD among women has increased over the last couple of decades, significant gaps in the understanding and management of the disease remain, particularly among black and Hispanic women. ${ }^{4,9,18,19,21}$ Indeed, the majority of women (approximately $85 \%$ ) in the STELLAR trial were white, and so results from this and other statin studies need to be interpreted with caution in women of ethnic minorities.

In addition, Mosca and colleagues have established that women with high cardiovascular risk rarely achieve established lipid goals in clinical practice. ${ }^{21}$ At a mean follow-up of 27 months in 8,353 high-risk women (CHD, CHD risk equivalent, or chronic kidney disease) in a managed care setting, only $7 \%$ had achieved AHA ideal lipid levels (12\% after 36 months). Despite the substantial evidence available during the study period that lipid-modifying therapy would benefit these women, such treatment was initiated in only $32 \%$ of patients, including $35 \%$ with LDL-C $\geq 100 \mathrm{mg} / \mathrm{dL}(\geq 2.6 \mathrm{mmol} / \mathrm{L})$.

Some of this undertreatment may be due to the misconception that risk factors in premenopausal women do not need to be managed aggressively and to the earlier belief, now disproved, ${ }^{22-24}$ that hormone replacement therapy reduced cardiovascular risk in postmenopausal women. Some undertreatment may be due to lack of awareness of overall 

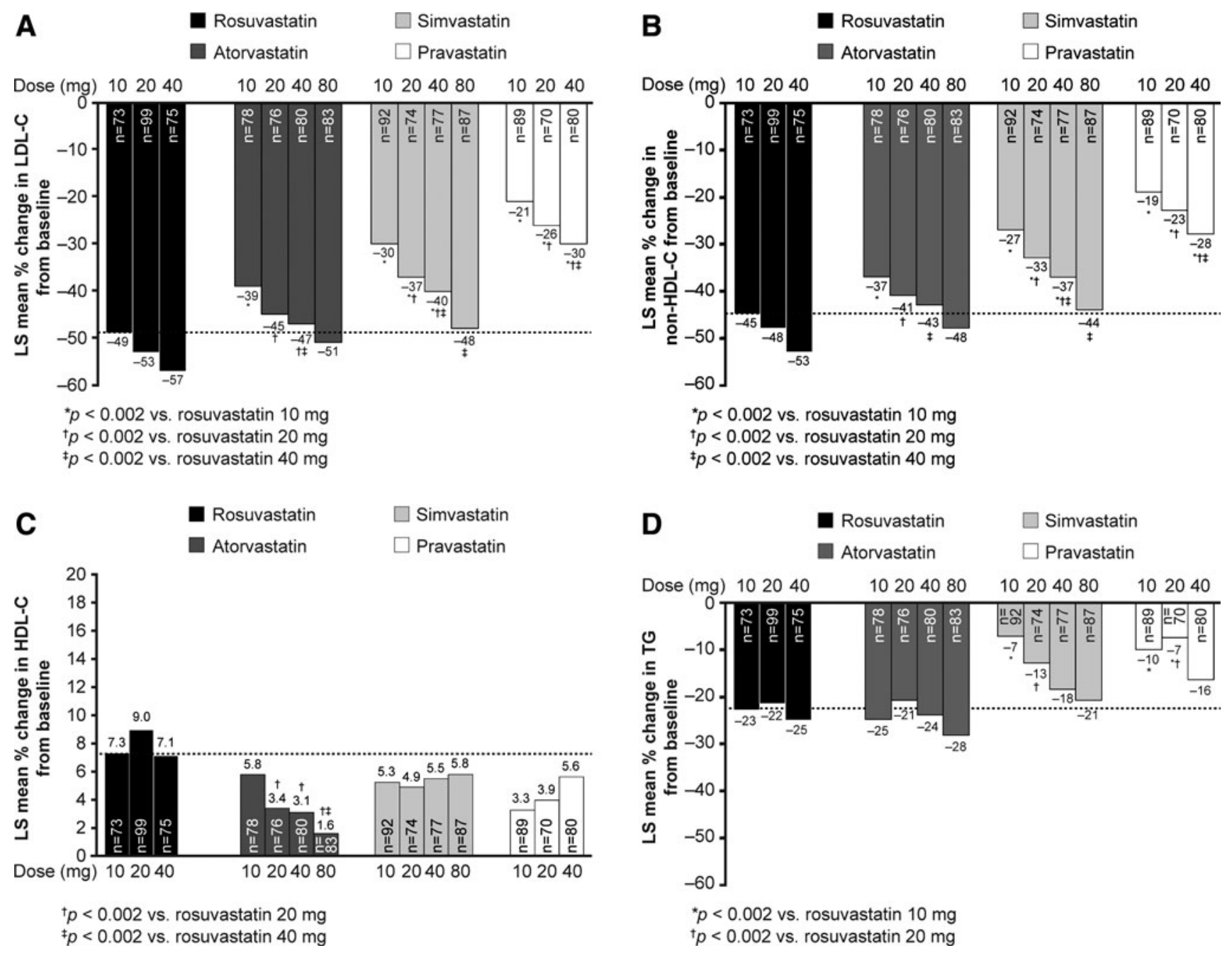

FIG. 2. (A) LS mean \% change from baseline in LDL-C at week 6 (LOCF). (B) LS mean \% change from baseline in nonHDL-C at week 6 (LOCF). (C) LS mean \% change from baseline in HDL-C at week 6 (LOCF). (D) LS mean \% change from baseline in TG at week 6 (LOCF). The dashed line refers to the least-squares mean percentage change for rosuvastatin $10 \mathrm{mg}$. HDL-C, high-density lipoprotein cholesterol; LDL-C, low-density lipoprotein cholesterol; LOCF, last observation carried forward; LS, least-squares; TG, triglycerides

cardiovascular risk in women ${ }^{18}$ and to differences in presentation and diagnosis of CVD in women compared with men. ${ }^{3}$

Our 6-week treatment period was not long enough to assess the effect on clinical events; therefore, our data cannot suggest a preferential advantage of one statin versus another in preventing cardiovascular events. However, based on the Cholesterol Treatment Trialists' meta-analysis of $>170,000$ patients in 26 prospective, randomized statin trials, which showed that every $39 \mathrm{mg} / \mathrm{dL}$ reduction in LDL-C led to a $22 \%$ (95\% CI: $0.76-0.80, p<0.0001)$ reduction in major vascular

Table 5. Adverse Events of Women in the Stellar Trial (Randomized Population)

\begin{tabular}{lcccc}
\hline AEs, n $(\%)$ & $\begin{array}{c}\text { Rosuvastatin } \\
10-40 m g \\
(\mathrm{n}=250)\end{array}$ & $\begin{array}{c}\text { Atorvastatin } \\
10-80 \mathrm{mg} \\
(\mathrm{n}=320)\end{array}$ & $\begin{array}{c}\text { Simvastatin } \\
10-80 \mathrm{mg} \\
(\mathrm{n}=331)\end{array}$ & $\begin{array}{c}\text { Pravastatin } \\
10-40 \mathrm{mg} \\
(\mathrm{n}=244)\end{array}$ \\
\hline All AEs & $110(44.0)$ & $181(56.6)$ & $168(50.8)$ & $130(53.3)$ \\
AEs leading to death & 0 & 0 & 0 & 0 \\
AEs leading to withdrawal & $7(2.8)$ & $14(4.4)$ & $10(3.0)$ & $8(3.3)$ \\
Serious AEs & $2(0.8)$ & $53(1.3)$ & $4(1.2)$ & $1(0.4)$ \\
Drug-related AEs & $28(11.2)$ & 0 & $36(10.9)$ & $25(10.2)$ \\
Drug-related AEs leading to death & 0 & $13(4.1)$ & 0 & 0 \\
Drug-related AEs leading to withdrawal & $5(2.0)$ & 0 & 0 & $7(2.1)$ \\
Drug-related serious AEs & 0 & & 0 & $0.9)$ \\
\hline
\end{tabular}

AEs, adverse events. 
events and a $10 \%$ (95\% CI: $0.87-0.93, p<0.0001)$ reduction in all-cause mortality, ${ }^{15}$ it would be predicted that greater LDL-C reductions would confer greater benefit in reducing cardiovascular events. Although women have been underrepresented in clinical end-point trials of statins, analyses of subgroups of women from these trials indicate that LDL-C reduction decreased cardiovascular event rates to a similar degree in women compared with that documented in men. ${ }^{14,16,25}$

A meta-analysis of 18 randomized controlled trials of statins in primary prevention found that statin intervention was associated with a lower cardiovascular event rate versus control and was similar in women and men (odds ratio [OR] $0.81,95 \%$ CI: $0.75-0.89 ; p<0.0001$ vs. OR $0.77,95 \%$ CI: $0.71-0.83 ; p<0.0001$, respectively). ${ }^{14}$ In addition, a sexspecific analysis of data from the Justification for the Use of Statins in Prevention: An Intervention Trial Evaluating Rosuvastatin (JUPITER) study assessed the efficacy and safety of rosuvastatin in apparently healthy individuals with raised high-sensitivity C-reactive protein. ${ }^{25}$ Overall, the absolute CVD rates in women for rosuvastatin and placebo (0.57 and 1.04 , respectively) were lower than those in men $(0.88$ and 1.54 , respectively), although the relative risk reduction associated with rosuvastatin was similar in women and men (hazard ratio [HR] $0.54,95 \%$ CI: $0.37-0.80 ; p=0.002$ vs. HR $0.58,95 \%$ CI: $0.45-0.73 ; p<0.001){ }^{25}$

Another meta-analysis compared the effect of statins in secondary prevention of CVD in men and women in 11 trials. ${ }^{16}$ Statin therapy (atorvastatin, fluvastatin, lovastatin, pravastatin, or simvastatin) was shown to be associated with a reduced risk of cardiovascular events in all outcomes for women (risk ratio [RR] 0.81, 95\% CI 0.74-0.89) and men (RR 0.82 , 95\% CI 0.78-0.85). However, there was no benefit with regard to stroke and all-cause mortality in women, although there was in men. ${ }^{16}$

Data on the impact of statin treatment on carotid intimamedia thickness are equally limited. A small study of 51 postmenopausal women aged $\geq 55$ years with dyslipidemia showed that women who received rosuvastatin $2.5 \mathrm{mg}$ per day for 12 months had significantly lower carotid intimamedia thickness values when compared with the women who received no statin therapy. ${ }^{26}$ These changes were in conjunction with significant decreases in LDL-C and highsensitivity C-reactive protein.

Overall, statins have proved to be generally well tolerated in most patients. ${ }^{27,28}$ Safety data from a number of largescale statin trials, when analyzed by gender, indicate that statins are generally well tolerated in women. ${ }^{14,16}$ Taken together, the available efficacy and safety data indicate that dyslipidemic women should receive appropriate statin therapy to reduce LDL-C levels and thereby reduce risk of CVD.

\section{Conclusion}

Our subanalysis of the STELLAR study confirms that women can achieve effective LDL-C reduction with statin therapy. Mean reductions in LDL-C were $\geq 49 \%$ with rosuvastatin doses of $10 \mathrm{mg}$ or higher, $\geq 39 \%$ with atorvastatin $10 \mathrm{mg}$ or higher, $\geq 30 \%$ with simvastatin $10 \mathrm{mg}$ or higher, and $\geq 21 \%$ with pravastatin $10 \mathrm{mg}$ or higher. Moreover, statin therapy was generally well tolerated in the women included in this study. These results suggest that substantial improvements in lipid levels are achievable with moderateto high-intensity statin therapy.

\section{Acknowledgments}

The authors would like to acknowledge Eric Justice of BioScience Communications, New York, New York, and Kerren Davenport, Prime Medica Ltd, Knutsford, Cheshire, United Kingdom, for editorial assistance in the preparation of this article funded by AstraZeneca, and Mike Palmer, formerly of AstraZeneca, for his assistance with statistical analyses. We would also like to acknowledge James Blasetto, $\mathrm{MD}$, for his contributions to the design of the STELLAR trial.

Each author has participated in the research and/or article preparation. All authors have approved the final article.

This research was supported by AstraZeneca.

\section{Author Disclosure Statement}

SJL has served as a consultant for AstraZeneca, Pfizer, and Merck and as an investigator for AstraZeneca and Pfizer. VAC and DAA are employees of AstraZeneca. KEF and FKW have no disclosures.

\section{References}

1. Go AS, Mozaffarian D, Roger VL, et al. Heart disease and stroke statistics-2014 update: A report from the American Heart Association. Circulation 2014;129:e28-e292.

2. Eaker ED, Chesebro JH, Sacks FM, et al. Cardiovascular disease in women. Circulation 1993;88:1999-2009.

3. Welty FK. Cardiovascular disease and dyslipidemia in women. Arch Intern Med 2001;161:514-522.

4. Mosca L, Benjamin EJ, Berra K, et al. Effectiveness-based guidelines for the prevention of cardiovascular disease in women-2011 update: A guideline from the American Heart Association. Circulation 2011;123:1243-1262.

5. Kannel WB, Wilson PW. Efficacy of lipid profiles in prediction of coronary disease. Am Heart J 1992;124:768-774.

6. Johnson CL, Rifkind BM, Sempos CT, et al. Declining serum total cholesterol levels among US adults. The National Health and Nutrition Examination Surveys. JAMA 1993;269:3002-3008.

7. Carr MC, Kim KH, Zambon A, et al. Changes in LDL density across the menopausal transition. J Investig Med 2000;48:245-250.

8. Castelli WP, Garrison RJ, Wilson PW, et al. Incidence of coronary heart disease and lipoprotein cholesterol levels. The Framingham Study. JAMA 1986;256:2835-2838.

9. Le NA, Brown WV, Davis WW, et al. Comparison of the relation of triglyceride-rich lipoproteins and muscular artery compliance in healthy women versus healthy men. Am J Cardiol 2005;95:1049-1054.

10. Austin MA, Hokanson JE, Edwards KL. Hypertriglyceridemia as a cardiovascular risk factor. Am J Cardiol 1998; 81:7B-12B.

11. Third Report of the National Cholesterol Education Program (NCEP) Expert Panel on Detection, Evaluation, and Treatment of High Blood Cholesterol in Adults (Adult Treatment Panel III) final report. Circulation 2002;106: 3143-3421.

12. Stone NJ, Robinson JG, Lichtenstein AH, et al. 2013 ACC/ AHA guideline on the treatment of blood cholesterol to reduce atherosclerotic cardiovascular risk in adults: A report of the American College of Cardiology/American 
Heart Association Task Force on Practice Guidelines. J Am Coll Cardiol 2014;63:2889-2934.

13. Fulcher J, O'Connell R, Voysey M, et al. Efficacy and safety of LDL-lowering therapy among men and women: Meta-analysis of individual data from 174,000 participants in 27 randomised trials. Lancet 2015;385:1397-1405.

14. Kostis WJ, Cheng JQ, Dobrzynski JM, Cabrera J, Kostis JB. Meta-analysis of statin effects in women versus men. J Am Coll Cardiol 2012;59:572-582.

15. Baigent C, Blackwell L, Emberson J, et al. Efficacy and safety of more intensive lowering of LDL cholesterol: A metaanalysis of data from 170,000 participants in 26 randomised trials. Lancet 2010;376:1670-1681.

16. Gutierrez J, Ramirez G, Rundek T, Sacco RL. Statin therapy in the prevention of recurrent cardiovascular events: A sexbased meta-analysis. Arch Intern Med 2012;172:909-919.

17. Schrott HG, Bittner V, Vittinghoff E, Herrington DM, Hulley S. Adherence to National Cholesterol Education Program Treatment goals in postmenopausal women with heart disease. The Heart and Estrogen/Progestin Replacement Study (HERS). The HERS Research Group. JAMA 1997;277:1281-1286.

18. Mosca L, Hammond G, Mochari-Greenberger H, Towfighi A, Albert MA. Fifteen-year trends in awareness of heart disease in women: Results of a 2012 American Heart Association national survey. Circulation 2013;127:1254-1263.

19. Jones PH, Davidson MH, Stein EA, et al. Comparison of the efficacy and safety of rosuvastatin versus atorvastatin, simvastatin, and pravastatin across doses (STELLAR* Trial). Am J Cardiol 2003;92:152-160.

20. Jones PH, Hunninghake DB, Ferdinand KC, et al. Effects of rosuvastatin versus atorvastatin, simvastatin, and pravastatin on non-high-density lipoprotein cholesterol, apolipoproteins, and lipid ratios in patients with hypercholesterolemia: Additional results from the STELLAR trial. Clin Ther 2004;26:1388-1399.

21. Mosca L, Merz NB, Blumenthal RS, et al. Opportunity for intervention to achieve American Heart Association guidelines for optimal lipid levels in high-risk women in a managed care setting. Circulation 2005;111:488-493.
22. Herrington DM, Reboussin DM, Brosnihan KB, et al. Effects of estrogen replacement on the progression of coronary-artery atherosclerosis. N Engl J Med 2000;343: 522-529.

23. Grady D, Herrington D, Bittner V, et al. Cardiovascular disease outcomes during 6.8 years of hormone therapy: Heart and Estrogen/progestin Replacement Study follow-up (HERS II). JAMA 2002;288:49-57.

24. Hulley S, Grady D, Bush T, et al. Randomized trial of estrogen plus progestin for secondary prevention of coronary heart disease in postmenopausal women. Heart and Estrogen/progestin Replacement Study (HERS) Research Group. JAMA 1998;280:605-613.

25. Mora S, Glynn RJ, Hsia J, et al. Statins for the primary prevention of cardiovascular events in women with elevated high-sensitivity C-reactive protein or dyslipidemia: Results from the Justification for the Use of Statins in Prevention: An Intervention Trial Evaluating Rosuvastatin (JUPITER) and meta-analysis of women from primary prevention trials. Circulation 2010;121:1069-1077.

26. Igase M, Kohara K, Tabara Y, et al. Low-dose rosuvastatin improves the functional and morphological markers of atherosclerosis in asymptomatic postmenopausal women with dyslipidemia. Menopause 2012;19:1294-1299.

27. Pasternak RC, Smith SC Jr, Bairey-Merz CN, et al. ACC/ AHA/NHLBI clinical advisory on the use and safety of statins. J Am Coll Cardiol 2002;40:567-572.

28. McKenney JM, Davidson MH, Jacobson TA, Guyton JR. Final conclusions and recommendations of the National Lipid Association Statin Safety Assessment Task Force. Am J Cardiol 2006;97:89C-94C.

Address correspondence to:

Francine $K$. Welty, $M D$

Beth Israel Deaconess Medical Center

Harvard Medical School

330 Brookline Avenue (Masco 433)

Boston, MA 02215

E-mail: fwelty@bidmc.harvard.edu 